\title{
siRNA-based targeting of antiapoptotic genes can reverse chemoresistance in P-glycoprotein expressing chondrosarcoma
}

\section{cells}

\author{
Dae Won Kim¹, Kyung-Ok Kim¹, Mike J Shin ${ }^{1}$, Jung Hee Ha ${ }^{1}$, \\ Sung Wook Seo ${ }^{1}$, Jay Yang ${ }^{2}$ and Francis Y Lee*1
}

Address: ${ }^{1}$ Department of Orthopaedic Surgery, The Center for Orthopaedic Research, Columbia University, New York, NY 10032, USA and 2Department of Anesthesiology, Columbia University, 630 West 168th Street New York, NY 10032, USA

Email: Dae Won Kim - kimdw1031@yahoo.com; Kyung-Ok Kim - kk2590@columbia.edu; Mike J Shin - mike.j.shin@gmail.com; Jung Hee Ha - jh2672@columbia.edu; Sung Wook Seo - sungwseo@gmail.com; Jay Yang - jy2029@columbia.edu; Francis Y Lee* - fl127@columbia.edu

* Corresponding author

Published: 15 May 2009

Molecular Cancer 2009, 8:28 doi:10.1186/1476-4598-8-28

This article is available from: http://www.molecular-cancer.com/content/8/I/28

(c) $2009 \mathrm{Kim}$ et al; licensee BioMed Central Ltd.

This is an Open Access article distributed under the terms of the Creative Commons Attribution License (http://creativecommons.org/licenses/by/2.0), which permits unrestricted use, distribution, and reproduction in any medium, provided the original work is properly cited.
Received: 4 December 2008

Accepted: I5 May 2009

\begin{abstract}
Background: High expression of P-glycoprotein is one of the well-known mechanisms of chemoresistance in chondrosarcomas. However, the role of antiapoptotic proteins, a common mechanism responsible for chemoresistance in other tumors, has not been well studied in chondrosarcomas. We examined the importance of P-glycoprotein and antiapoptotic proteins in the chemoresistance to doxorubicin of two Grade II chondrosarcoma cell lines, JJ0 I 2 and SW I 353.

Results: We confirmed that both chondrosarcoma cell types expressed P-glycoprotein and antiapoptotic proteins ( $\mathrm{Bcl}-2, \mathrm{Bcl}-\mathrm{xL}$ and XIAP). siRNA knockdown as well as pharmacologic inhibitors of cell survival proteins (Bcl-2, Bcl-xL and XIAP) enhanced apoptosis of chemoresistant chondrosarcoma cells by up to 5.5 fold at $0.1 \mu \mathrm{mol}$ and 5.5 fold at I $\mu$ mol doxorubicin. These chemosensitizing effects were comparable to those of P-glycoprotein inhibition by siRNA or pharmacologic inhibitor.

Conclusion: These findings suggest that antiapoptotic proteins play a significant role in the chemoresistance of chondrosarcoma cells independent of P-glycoprotein. Based on the results, a new siRNA-based therapeutic strategy targeting antiapoptotic genes can be designed to overcome the chemoresistance of chondrosarcomas which is often conferred by P-glycoprotein.
\end{abstract}

\section{Background}

Chondrosarcoma is the second most common sarcoma arising in bones and the main treatment is surgical resection with a wide margin. However, there is no effective therapeutic option for metastatic chondrosarcoma patients since chondrosarcoma is resistant to both chemotherapy and radiation therapy $[1,2]$. Therefore, it is nec- essary to explore new therapeutic approaches for metastatic and surgically unresectable chondrosarcoma cases. P-glycoprotein, a product of multidrug resistant gene 1 , and antiapoptotic protein overexpression are two common mechanisms of chemoresistance in tumor cells. It has already been reported that chondrosarcoma cells highly express P-glycoprotein and antiapoptotic proteins 
(Bcl-2, Bcl-xL, XIAP) [3-6]. The role of P-glycoprotein in drug efflux has been identified as one of the mechanisms for chemoresistance in human chondrosarcoma cells $[3,7]$, while the function of antiapoptotic genes in chemoresistance has not been elucidated.

P-glycoprotein is a transmembrane ATP-dependent pump that transports drugs out of cells as protection against toxins. Tumor cells exposed to a single cytotoxic drug are resistant to structurally and functionally unrelated drugs, and P-glycoprotein is largely responsible for this multidrug resistance (MDR) $[8,9]$. MDR resulting from the overexpression of P-glycoprotein has been reported in different types of soft tissue sarcomas (eg, malignant fibrous histiocytoma, liposarcoma, leiomyosarcoma, Ewing's sarcoma) and hematologic malignancies (eg, multiple myeloma, acute myeloid or lymphoblastic leukemia) [10,11]. In addition to drug transportation, Pglycoprotein overexpressing cells exhibit abrogation of mitochondrial cytochrome $c$ release and caspase- 3 activation, which may be dependent on Bcl-xL overexpression [12]. Bcl-xL, one of the well-known antiapoptotic Bcl-2 family members, controls apoptosis by blocking the release of cytochrome $\mathrm{c}$ from the mitochondria. Furthermore, the activation of caspases, the effector molecules of apoptosis, is dependent on this cytochrome c release. It has been reported that the inhibition of apoptosis can lead to tumorigenesis and resistance to chemotherapy and radiotherapy in carcinomas $[13,14]$. Although the role of antiapoptotic proteins in the chemoresistance of chondrosarcoma is not well understood, the overexpression of antiapoptotic proteins ( $\mathrm{Bcl}-2, \mathrm{Bcl}-\mathrm{xL}, \mathrm{XIAP})$ is one of the mechanisms of radiation resistance in chondrosarcoma cells [4]. Since chemotherapeutic agents and radiation therapy both induce apoptotic cell death $[15,16]$, antiapoptotic proteins may contribute to chemoresistance, as well. Several studies have suggested that antiapoptotic proteins have a major role in chemoresistance $[17,18]$. Chondrosarcoma cells with MDR properties conferred by membrane-bound P-glycoprotein still have a significant amount of cytoplasmic levels of doxorubicin remaining after doxorubicin treatment and washout, which further supports the involvement of antiapoptotic proteins in chemoresistance [7].

Based on these findings, we hypothesize (1) antiapoptotic proteins mediate chemoresistance in chondrosarcoma cells and (2) the knockdown of these proteins, as well as P-glycoprotein, would enhance chemosensitivity to the doxorubicin remaining in the cells.

\section{Results \\ Chondrosarcoma cells are resistant to chemotherapy}

In order to verify the chemoresistance of chondrosarcoma cells, we treated well-known human grade II chondrosar- coma cells, SW1353 and JJ012 [19-21], with doxorubicin in vitro. Doxorubicin treatment did not increase apoptosis in chondrosarcoma cells while human embryonic kidney (HEK) cells were undergoing robust apoptosis (Figure 1A). Normal chondrocyte cells also exhibited chemoresistance, suggesting that chondrocytes, in general, are chemoresistant. To confirm P-glycoprotein and antiapoptotic protein expression as a possible mechanism of chemoresistance in chondrosarcoma, we measured $\mathrm{P}$ glycoprotein, Bcl-2, Bcl-xL and XIAP expression by immunoblotting (Figure 1B). Normal chondrocytes and chondrosarcoma cells express all these proteins, suggesting that both P-glycoprotein and antiapoptotic proteins may contribute to doxorubicin resistance.

To investigate the effect of doxorubicin, we measured protein expression after doxorubicin treatment (Figure 1C).

A

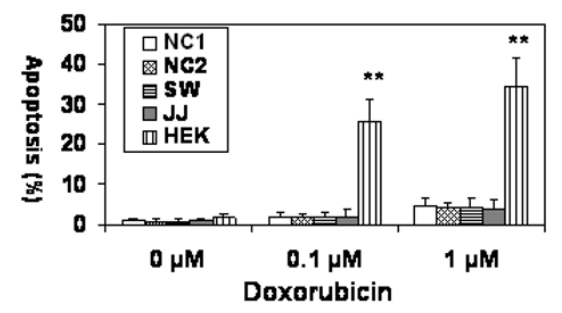

B

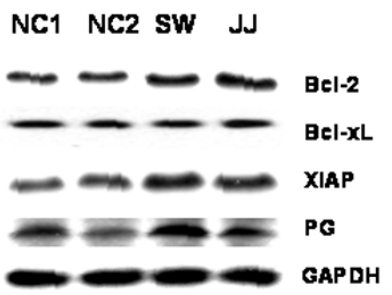

C

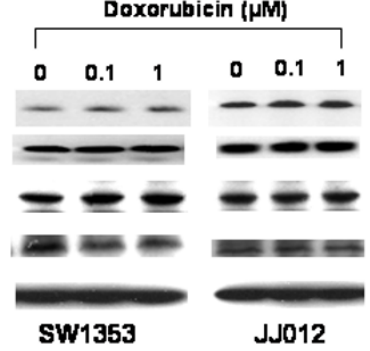

\section{Figure I}

Doxorubicin resistance and expression of antiapoptotic protein and P-glycoprotein in chondrosarcoma cells. (A) Detection of apoptosis by flow cytometry after doxorubicin treatment. Two normal articular chondrocytes ( $\mathrm{NCl}$ and $\mathrm{NC2}$ ) and two chondrosarcoma cells (SW:

SWI353 and JJ: JJ0I2) showed chemoresistance when compared to human embryonic kidney cells (HEK). (B) Immunoblotting anti-apoptotic proteins ( $\mathrm{Bcl}-2, \mathrm{Bcl}-\mathrm{xL}$, and $\mathrm{XIAP})$ and P-glycoprotein. Bcl-2, Bcl-xL, XIAP and P-glycoprotein expressions were verified in two normal chondrocytes $(\mathrm{NCl}$ and NC2) and two chondrosarcoma cells (SW: SWI 353, J]: JJ0I2). (C) Immunoblotting anti-apoptotic proteins (Bcl-2, $\mathrm{Bcl}-\mathrm{xL}$, and $\mathrm{XIAP}$ ) and $\mathrm{P}$-glycoprotein in two chondrosarcoma cells after doxorubicin treatment. Bcl-2, Bcl-xL, XIAP and $\mathrm{P}$-glycoprotein expressions were not changed significantly after doxorubicin treatment. 
Doxorubicin treatment did not significantly change expression levels of P-glycoprotein and antiapoptotic proteins in both chondrosarcoma cell types.

\section{P-glycoprotein is expressed on the cell surface and expels doxorubicin from the cells}

Membrane-bound P-glycoprotein expression and doxorubicin uptake were measured by flowcytometry. P-glycoprotein was present on the cell surface of both chondrosarcoma cell types (Figure 2A). Doxorubicin has inherent autofluorescent (excitation wavelength: $480 \mathrm{~nm}$, emission wavelength: $580 \mathrm{~nm}$ ) and intracellular doxorubicin uptake was measured. Our results show that as doxorubicin dose increased, the number of fluorescent cells increased (Figure 2B). To examine the functional activity of P-glycoprotein, we measured doxorubicin levels in chondrosarcoma cells after doxorubicin washout. Doxorubicin levels decreased in cells in a time dependant manner (Figure 2C). However, a substantial amount of doxorubicin still remained 24 hours after doxorubicin washout (Figure 2C). These data suggest that P-glycoprotein may not be the only responsible mechanism for chemoresistance by chondrosarcoma cells.

\section{Pharmacologic inhibitors of antiapoptotic protein and $\mathbf{P}$ - glycoprotein enhance doxorubicin sensitivity}

We showed that P-glycoprotein does not completely eliminate doxorubicin from chondrosarcoma cells. We
A
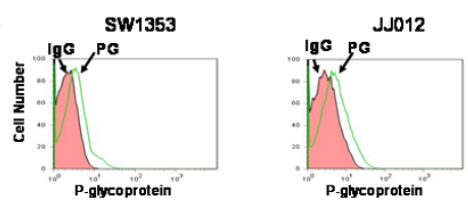

B

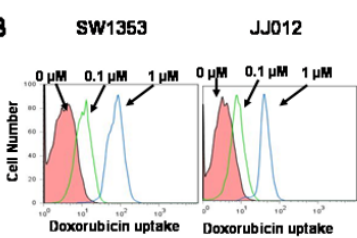

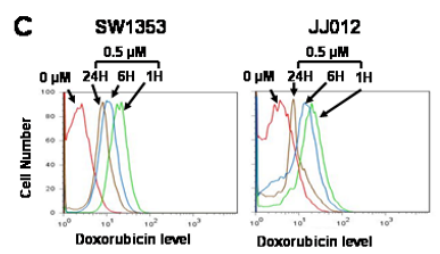

Figure 2

Cell surface expression of P-glycoprotein and doxorubicin uptake and efflux in chondrosarcoma cells. (A) Cell surface P-glycoprotein expression was detected by flow cytometric analysis. Cell surface P-glycoprotein staining was positive in two chondrosarcoma cells. (IgG: isotype $\lg \mathrm{G}$ control, PG: P-glycoprotein antibody) (B) Doxorubicin uptake was measured in two chondrosarcoma cells. Doxorubicin uptake increased as doxorubicin concentration was increased in the two chondrosarcoma cell lines. (C) Functional assay of P-glycoprotein was performed after doxorubicin washout. Doxorubicin levels were measured at I, 6 and 24 hours after washout after I hour treatment. Doxorubicin levels decreased in a time dependant manner. hypothesize that antiapoptotic proteins have a critical role in chemoresistance since a significant amount of doxorubicin remains within chondrosarcoma cells. To test our hypothesis, we treated cells with inhibitors of antiapoptotic proteins and P-glycoprotein in the presence or absence of doxorubicin. First, we performed a doseresponse experiment using 3 different doses of pharmacologic inhibitors based on previously published reports in order to find an optimal concentration that is least cytotoxic [22-24]. There were no significant changes in the rate of apoptosis with $10 \mu \mathrm{M}$ of Bcl-2 inhibitor (2.36 \pm $0.67 \%), 10 \mu \mathrm{M}$ of C-4 (3.19 $\pm 0.91 \%)$ or $10 \mu \mathrm{M}$ of embelin $(3.53 \pm 1.75 \%)$ when compared with the DMSO treated control group $(1.53 \pm 0.74 \%)$. Based on these data, chondrosarcoma cells were treated with $10 \mu \mathrm{M}$ of Bcl-2 inhibitor, $10 \mu \mathrm{M}$ of C-4 (P-glycoprotein inhibitor) or $10 \mu \mathrm{M}$ of embelin (XIAP inhibitor) and two different concentrations of doxorubicin $(0.1 \mu \mathrm{M}$ and $1 \mu \mathrm{M})$. Apoptosis rates were measured to investigate whether or not inhibition of antiapoptotic proteins or P-glycoprotein would enhance doxorubicin sensitivity in chondrosarcoma cells. While the DMSO treated chondrosarcoma cells exhibited chemoresistance (SW1353; $2.42 \pm 0.96 \%$ at $0.1 \mu \mathrm{M}, 4.24 \pm 2.53 \%$ at $1 \mu \mathrm{M}$. JJ012; $2.5 \pm 0.76 \%$ at 0.1 $\mu \mathrm{M}, 4.26 \pm 0.9 \%$ at $1 \mu \mathrm{M})$, inhibition of Bcl-2, XIAP and P-glycoprotein enhanced the chemosensitivity by up to 4.5 fold (C-4 treated JJ012: $11.46 \pm 3.37 \%, \mathrm{p}<0.05)$ at 0.1 $\mu \mathrm{M}$ and 4 fold (C-4 treated SW1353: $17.36 \pm 1.58 \%, \mathrm{p}<$ $0.05)$ at $1 \mu \mathrm{M}$ in comparison to each control group on flowcytometric examination (Figures $3 \mathrm{~A}$ and $3 \mathrm{~B}$ ). In addition, the combination of inhibitors for antiapoptotic proteins and P-glycoprotein enhanced the chemosensitivity by up to 5.5 fold (Bcl-2 inhibitor+C-4 treated JJ012: 13.93 $\pm 2.76 \%, \mathrm{p}<0.01$ ) at $0.1 \mu \mathrm{M}, 5.5$ fold (embelin+C-4 treated SW1353:23.51 $\pm 3.50 \%, \mathrm{p}<0.01)$ at $1 \mu \mathrm{M}$. The increase in the chemosensitizing effect by combinatorial use of antiapoptotic protein and P-glycoprotein inhibitors was maximal when P-glycoprotein (C-4) and XIAP (embelin) were inhibited simultaneously in doxorubicin treatment (Figure 3B).

To examine the mechanism of doxorubicin and inhibitor induced cell death in chondrosarcoma cells, we obtained cytosolic and mitochondrial fractions and measured cytochrome c expression after treatment of doxorubicin in the presence or absence of inhibitors. Doxorubicin treatment with inhibitors of antiapoptotic protein or P-glycoprotein induced cytochrome $\mathrm{c}$ release from mitochondria to cytosol (Figure 3C). However, doxorubicin treatment alone did not trigger mitochondrial cytochrome c release significantly. These data suggest inhibition of antiapoptosis proteins and P-glycoproteins enhance doxorubicin sensitivity by the cytochrome c release mechanism.

There is a possibility that antiapoptotic protein inhibitors treatment may change the function or the expression of $\mathrm{P}$ - 


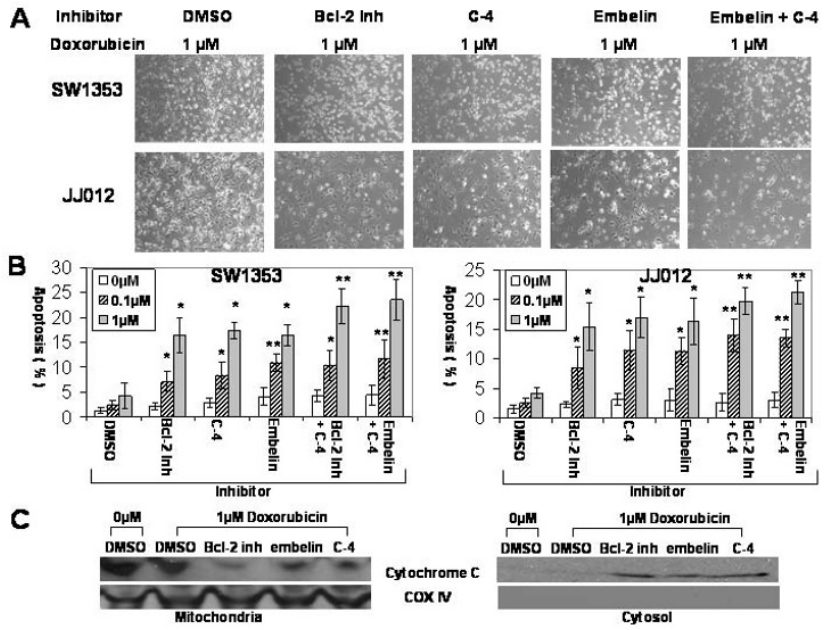

Figure 3

Apoptosis after inhibitor and doxorubicin treatment. (A) Microscopic pictures after inhibitor and doxorubicin treatment are shown. Chondrosarcoma cells treated with 10 $\mu \mathrm{M}$ of $\mathrm{Bcl}-2$ inhibitor, $10 \mu \mathrm{M}$ of C-4 (P-glycoprotein inhibitor) or $10 \mu \mathrm{M}$ of embelin (XIAP inhibitor) showed more apoptotic cells than control groups after doxorubicin treatment. (Bcl-2 inh: $\mathrm{Bcl}-2$ inhibitor, original magnification $\times 100)$. (B) The effect of inhibitors on chemosensitivity in chondrosarcoma cells is shown. Inhibitor treatment enhanced chemosensitivity. Inhibitor treated chondrosarcoma cells demonstrated increased apoptosis after doxorubicin treatment in comparison to the control groups (up to 4.5 fold increase). Combination treatment of inhibitors ( $\mathrm{Bcl}-2$ inh + C-4 and embelin + C-4) showed significant increase in apoptosis. (Bcl-2 inh: $\mathrm{Bcl}-2$ inhibitor, $*_{\text {: }} \mathrm{p}<0.05$ and $* *$ : $\mathrm{p}<0.0 \mathrm{I}$ ) (C) Immunoblotting demonstrates cytochrome $c$ release from mitochondria to cytosol after treatment with doxorubicin and inhibitors. Cytochrome oxidase IV (COX IV) serves as a marker for mitochondria.

glycoprotein instead of the direct effect on antiapoptotic proteins in P-glycoprotein expressing chondrosarcoma cells. To investigate the possibility, we performed doxorubicin efflux assay and measured P-glycoprotein mRNA expression by RT-PCR after treatment of antiapoptotic protein inhibitors. Antiapoptotic inhibitors treatment (Bcl-2 inhibitor, embelin) changed P-glycoprotein function, but it was not significant (Figure 4A). Only C-4 treatment (P-glycoprotein inhibitor) inhibited doxorubicin efflux significantly compared with DMSO control (Figure $4 \mathrm{~A})$. None of the inhibitors treatment changed mRNA expression of P-glycoprotein (Figure 4B). These data suggest antiapoptotic proteins and P-glycoprotein may be independent chemoresistant mechanisms in chondrosarcoma cells.

\section{Antiapoptotic and P-glycoprotein gene silencing enhances doxorubicin sensitivity}

We also tested our hypothesis that both antiapoptotic proteins and P-glycoprotein play an important role in the
A
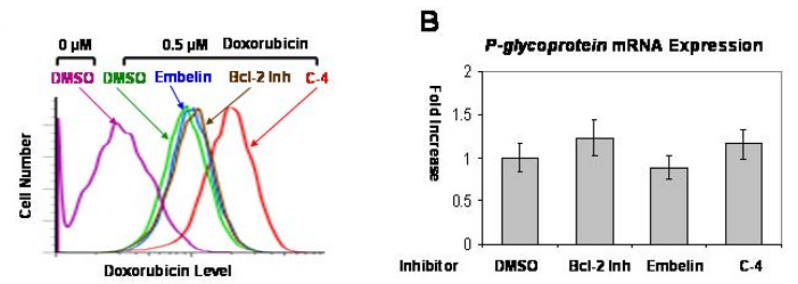

Figure 4

Function and mRNA expression of P-glycoprotein after inhibitor treatment. (A) Doxorubicin efflux was measured after inhibitor treatment. Only C-4 (P-glycoprotein inhibitor) treatment inhibited doxorubicin efflux significantly. (Bcl-2 inh: $\mathrm{Bcl}-2$ inhibitor) (B) mRNA expression of $P$ glycoprotein was measured by RT-PCR. All inhibitors did not change mRNA expression of $P$-glycoprotein. mRNA expression of $P$-glycoprotein of each inhibitor treatment was divided by mRNA expression of DMSO control. (Bcl-2 inh: Bcl-2 inhibitor).

chemoresistance of chonodrosarcoma cells using siRNA. First, we examined intracellular uptake of siRNA which has a fluorescent tag. Chondrosarcoma cells showed fluorescence in the cytoplasm 24 hours after transfection with fluorescence protein tagged siRNA (Figure 5A). We examined the P-glycoprotein drug-exporting function after $P$ glycoprotein gene silencing. P-glycoprotein knockdown decreased doxorubicin efflux significantly (Figure 5B). Next, immunoblotting was used to confirm siRNA's target gene knockdown effect (Figure 5C). Target protein expression of each siRNA was significantly decreased in comparison to the control groups. To determine whether targeting antiapoptotic genes may affect the expression of P-glycoprotein or vice versa, protein expression was measured by quantifying the density of immunoblot bands adjusted to GAPDH using ImageJ software and mRNA expression of P-glycoprotein was measured by RT-PCR after siRNA treatment. Targeting any of the antiapoptic genes did not change mRNA and protein expression of P-glycoprotein gene significantly compared with non-silencing control (Figure 5D and Figure 6). Targeting the P-glycoprotein gene did not change any of the antiapoptotic proteins expression, either (Figure 6). These data support our inhibitors experiment finding (Figure 4A, 4B), which suggests antiapoptotic proteins and P-glycoprotein are independent doxorubicin resistant mechanisms in chondrosarcoma cells.

We calculated the following target gene knockdown efficiency with $1 \mu \mathrm{g} / \mathrm{ml}$ of siRNA (SW1353; Bcl-2: $39 \pm 5.1 \%$, Bcl-xL: $72 \pm 10.3 \%$, XIAP: $66 \pm 12.2 \%, P$-glycoprotein: $47 \pm$ 6.8\%. JJ012; Bcl-2: $57 \pm 10.2 \%, B c l-x L: 75 \pm 11.7 \%$, XIAP: $70 \pm 9.6 \%$, P-glycoprotein: $62 \pm 9.9 \%)$. Apoptosis rates were measured with annexin $\mathrm{V}$ after chondrosarcoma cells were treated with $1 \mu \mathrm{g} / \mathrm{ml}$ of siRNA and two different concen- 
A
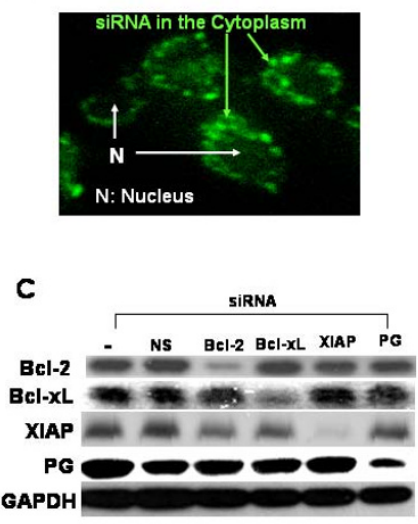

D

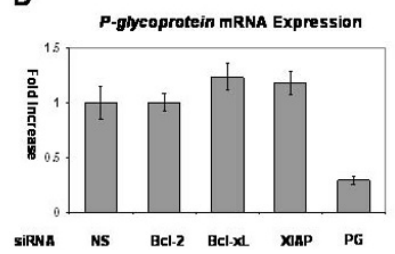

Figure 5

siRNA gene silencing. (A) A fluorescent microscopy picture demonstrates intracellular localization of siRNA tagged with green fluorescent protein (GFP). Most GFP tagged siRNA was seen in the cytoplasm while the nuclei $(\mathrm{N})$ lack green fluorescence. (B) Doxorubicin level was measured after $P$-glycoprotein siRNA treatment. P-glycoprotein siRNA treatment increased doxorubicin level at 0.1 and I $\mu M$ in comparison to Non-Silencing control siRNA. (NS: NonSilencing siRNA, PG: P-glycoprotein siRNA) (C) Immunoblotting demonstrates decreased expression of $\mathrm{Bcl}-2, \mathrm{Bcl}-\mathrm{xL}$, XIAP and P-glycoprotein by siRNA. (-: carrier only, NS: Nonsilencing siRNA, PG: P-glycoprotein) (D) Targeting antiapoptotic gene ( $B C l-2, B C l-x L$ and XIAP) did not change mRNA expression of $P$-glycoprotein. Only P-glycoprotein siRNA treatment decreased mRNA expression of $P$-glycoprotein. mRNA expression of $P$-glycoprotein of each siRNA treatment was divided by mRNA expression of nonsilencing control. (NS: Nonsilencing siRNA, PG: P-glycoprotein).

trations of doxorubicin $(0.1 \mu \mathrm{M}$ and $1 \mu \mathrm{M})$. While the untreated chondrosarcoma cells exhibited chemoresistance, $B c l-2, B c l-x L$ and XIAP gene silencing enhanced chemosensitivity by up to 2.7 fold (XIAP siRNA treated JJ012: $9.97 \pm 1.47 \%, \mathrm{p}<0.05)$ at $0.1 \mu \mathrm{M}$ and 3.3 fold (Bcl$x L$ siRNA treated JJ012: $16.90 \pm 3.84 \%, \mathrm{p}<0.01)$ at $1 \mu \mathrm{M}$ in comparison to each nonsilencing control group (JJ012: $3.63 \pm 1.27 \%$ at $0.1 \mu \mathrm{M}, 5.12 \pm 1.49 \%$ at $1 \mu \mathrm{M})$ on flow cytometric examination (Figure 7A and 7B). P-glycoprotein gene silencing also enhanced chemosensitivity significantly at $0.1 \mu \mathrm{M}($ SW1353: $9.65 \pm 1.98 \%, \mathrm{JJ} 012: 9.83 \pm$ $1.72 \%, \mathrm{p}<0.05)$ and $1 \mu \mathrm{M}(\mathrm{SW} 1353: 14.12 \pm 3.03 \%$, JJ012: $17.99 \pm 3.77 \%, p<0.05)$ in comparison to each nonsilencing control group. Additionally, dual gene silencing of both the antiapoptotic gene and P-glycoprotein gene enhanced chemosensitivity by up to 4.1 fold $(X I A P+P G$ siRNA treated JJ012: $15.04 \pm 1.60 \%, \mathrm{p}<0.01)$ at $0.1 \mu \mathrm{M}$, and 4.2 fold (XIAP+PG siRNA treated JJ012: $21.96 \pm 2.79 \%, \mathrm{p}<0.01)$ at $1 \mu \mathrm{M}$. Interestingly, antiapoptotic or P-glycoprotein gene silencing without doxorubicin
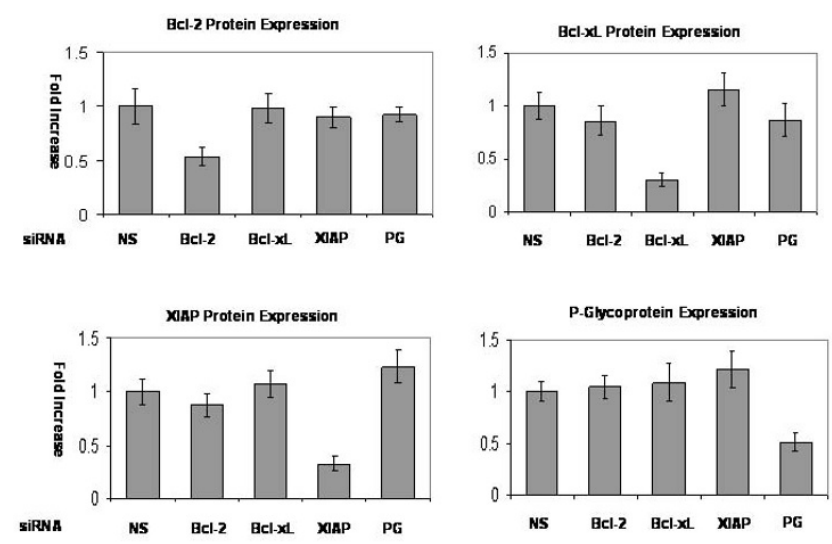

Figure 6

Quantification of protein expression after siRNA gene silencing. Protein expression was quantified by ImageJ software after siRNA gene silencing. Only targeted gene expression changed significantly compared with gene expression of non-silencing control. Non-target gene expression did not change significantly. (NS: Nonsilencing siRNA, PG: P-glycoprotein).

treatment caused a very modest induction of apoptosis (Figure 7B). Overall, the use of target protein specific siRNA and doxorubicin increased chemosensitivity by 4 to 14 folds in comparison to untreated cells.

\section{Antiapoptotic or P-glycoprotein gene silencing with chemotherapy decreases cell survival and proliferation}

Tumor recurrence is a prognostic factor which negatively affects clinical outcome following radiation or chemotherapy. We hypothesize that anti-apoptotic or P-glycoprotein gene silencing in combination with chemotherapy decreases both survival and proliferation of chondrosarcoma cells. Clonogenic cell survival assays were conducted and showed that chondrosarcoma cells still have the ability to proliferate and form multiple colonies after doxorubicin treatment (Figure 8). When antiapoptotic or P-glycoprotein genes were silenced in cells that underwent chemotherapy, the number of colonies decreased significantly $(\mathrm{p}<0.05)$. Antiapoptotic gene silencing decreased colony formation by up to three fold $(\mathrm{p}<0.05)$ at $0.1 \mu \mathrm{M}$, in comparison to the control group. At the highest dose of doxorubicin $(1 \mu \mathrm{M})$, there was no significant colony formation in any siRNA treated group.

\section{Discussion}

There is no effective treatment for metastatic or unresectable chondrosarcomas due to the chemo- and radioresistant properties of such cancers. In this regard, a better understanding of the molecular mechanisms responsible for chemo- and radioresistance is necessary to develop novel therapeutic strategies. Failure of chemotherapy results from both patient and tumor variances. The host 
A
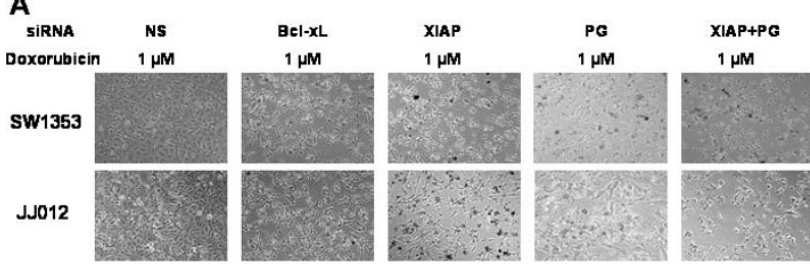

B
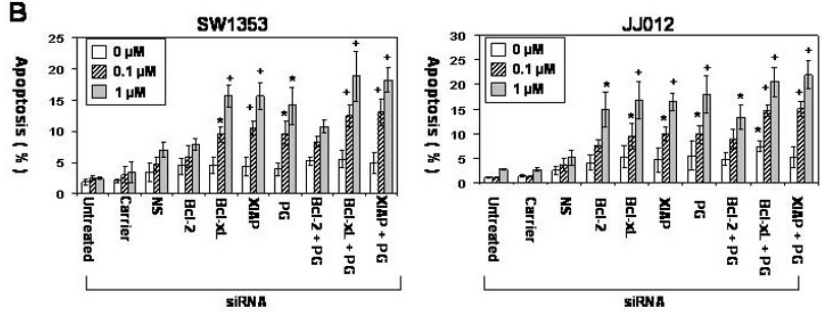

Figure 7

Apoptosis after siRNA and doxorubicin treatment. (A) Microscopic pictures after siRNA and doxorubicin treatment are shown. Chondrosarcoma cells treated with siRNAs showed more apoptotic cells than control groups after doxorubicin treatment (NS: nonsilencing siRNA, PG: P-glycoprotein, original magnification $\times 100)$. (B) The effect of gene silencing on chemosensitivity in chondrosarcoma cells is shown. siRNA treatment enhanced chemosensitivity. siRNA treated chondrosarcoma cells demonstrated increased apoptosis after doxorubicin treatment in comparison to the control groups (up to 3.3 fold increase). Dual gene silencing ( $\mathrm{BCl}-$ $x L+P G$ and XIAP +PG siRNA) also increased apoptosis significantly. (NS: nonsilencing siRNA, PG: P-glycoprotein, *: $p<$ $0.05,+: p<0.01$, Nonsilencing siRNA treated group was used as a control for $\mathrm{p}$-value.)

factors include poor absorption, rapid metabolism and insufficient drug delivery to the tumor site, while the tumor factors include the loss of cell surface receptors or drug transport proteins, specific metabolism of chemotherapy drugs, mutation of the specific target of drugs, and the increase in drug efflux [25]. Drug efflux has been studied extensively, since it has the most relevance to multidrug resistance. Consequently, it is believed that the major mechanism of multidrug resistance in tumor cells is Pglycoprotein expression [26]. Several in vitro studies have already reported that most chondrosarcoma cells express P-glycoprotein to confer MDR [5,7]. Our experiments have confirmed this as previously reported by other groups (Figure 1B). Doxorubicin resistant normal cartilage and chondrosarcoma cells express high levels of antiapoptotic proteins as well as P-glycoprotein, suggesting that both P-glycoprotein and antiapoptotic proteins may contribute to doxorubicin resistance.

P-glycoprotein is located on the plasma membrane which removes cytotoxic drugs from the cell. It is believed to be the main mechanism of chemoresistance in P-glycopro- tein expressing tumors regardless of antiapoptotic gene expression since cytotoxic drugs were thought to be removed before antiapoptotic proteins would work. However, our data reveals that doxorubicin uptake increases with higher doses in P-glycoprotein expressing chondrosarcoma cells (Figure 2B) and antiapoptotic protein inhibition and gene silencing enhanced doxorubicin sensitivity independent of P-glycoprotein (Figures 3B and 7B). Additionally, significant amounts of doxorubicin still remained in chondrosarcoma cells 24 hours after doxorubicin washout (Figure 2C).

Our results suggest that antiapoptotic proteins play a role in the chemoresistance of chondrosarcoma cells by enhancing cell survival in addition to P-glycoprotein. These antiapoptotic proteins and P-glycoprotein are two independent chemoresistance mechanisms in chondrosarcoma cells since targeting antiapoptotic proteins did not have any effect on the activity, mRNA expression level and protein expression level of P-glycoprotein (Figure 4A, B, $5 \mathrm{D}$ and 6 ) and targeting P-glycoprotein did not change the expression level of antiapoptotic proteins, either (Figure 6). The two independent mechanisms are closely related in terms of a cell death pathway by blocking cytochrome $\mathrm{c}$ release for doxorubicin resistance in chondrosarcoma cells (Figure 3C and 9). We also found targeting both P-glycoprotein and antiapoptotic protein with doxorubicin treatment showed additive effect rather than synergistic effect (Figure 3B and 7B). This may be due to the fact that apoptosis which results from targeting antiapoptotic proteins, induces the cleavage of P-glycoprotein [27] which may weaken the effect of targeting P-glycoprotein.

Among the antiapoptotic genes screened, the knockdown of $B c l-x L$ and XIAP enhanced doxorubicin sensitivity as effectively as $P$-glycoprotein and the combined knockdown of $B c l$-xL with P-glycoprotein and XIAP with P-glycoprotein were significantly effective in our dual gene silencing group (Figure 7A and 7B). This may be explained by the fact that Bcl-xL and XIAP overexpression in P-glycoprotein expressing tumor cells has been associated with a much stronger resistance to treatment and a worse prognosis $[12,28]$. Moreover, apoptosis itself induces the cleavage of P-glycoprotein, which may enhance apoptotic sensitivity [27].

Yet, the knockdown of $\mathrm{Bcl}-2$ did not induce significant apoptosis in SW1353 chondrosarcoma cells (Figure 7B) while Bcl-2 inhibitor treatment enhanced doxorubicin sensitivity in SW1353 cells (Figure 3B). This may be due to the low knockdown efficiency of Bcl-2 (SW1353; Bcl-2: $39 \pm 5.1 \%$, Bcl-xL: $72 \pm 10.3 \%$, XIAP: $66 \pm 12.2 \%$, P-glycoprotein: $47 \pm 6.8 \%$. JJ012; Bcl-2: $57 \pm 10.2 \%, B c l-x L: 75 \pm$ 11.7\%, XIAP: $70 \pm 9.6 \%$, P-glycoprotein: $62 \pm 9.9 \%)$. In addition, Bcl-2 inhibitor inhibits Bcl-xL as well as Bcl-2 

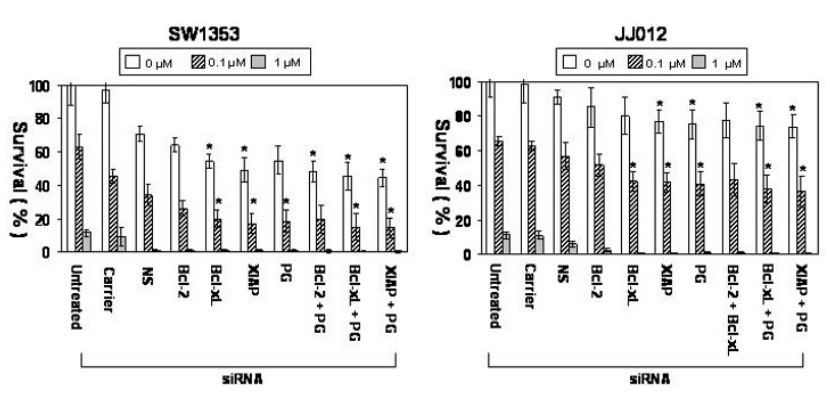

Figure 8

Clonogenic survival after siRNA and doxorubicin treatment. Clonogenic survival after chemotherapy and siRNA is shown. siRNA treatment with chemotherapy decreases colony formation by two times. Combinatorial siRNA treatments ( $B c l-x l+P G$ or XIAP + PG siRNA) inhibited colony formation effectively after doxorubicin treatment. (PG: P-glycoprotein, *: $\mathrm{p}<0.05$ ).

since Bcl-2 inhibitor competes with Bak BH3 peptide for binding to Bcl-2 and Bcl-xL [24]. Consequently, we could not establish its role in chemoresistance. There are several factors which can explain this discrepancy in the knockdown efficiency of each target protein. siRNA efficiency can be determined by the cell type, passage number, confluency of cells, turnover rate of proteins, and the stability of proteins [29]. Each protein has different turnover rates and stabilities which is why our siRNA knockdown efficiency is quite different for each target protein.

Although chondrosarcoma cells are resistant to doxorubicin, clonogenic survival data showed that the colony numbers of the untreated groups were decreased significantly at 0.1 and $1 \mu \mathrm{M}$ of doxorubicin. This may be the result of a number of factors including trypsinization and the small number of cells seeded, in addition to doxorubicin's effect.

We used Grade II chondrosarcoma cells which are well characterized and have been widely used by other investigators [19-21]. Grade III chondrosarcoma cells could be a more attractive experimental model but grade III chondrosarcoma cells often lose cartilage phenotypes with more heterogeneous cellularity. Hence, grade II chondrosarcomas were the best choice for our purposes since they have a high resistance to both chemo- and radiotherapy, metastatic potential and a high recurrence rate but still maintain the cartilaginous phenotype. Although our study was limited to Grade II chondrosarcomas, the proposed therapeutic concept may be relevant to other high grade sarcomas including Grade III chondrosarcomas which overexpress P-glycoprotein and antiapoptotic proteins $[3,6]$.

In summary, our data suggest that antiapoptotic proteins as well as P-glycoprotein confer chemoresistance to P- glycoprotein expressing chondrosarcoma cells (Figure 9). As a result, antiapoptotic gene and P-glycoprotein silencing via siRNA possibly could be used as a molecular adjuvant therapy for metastatic or surgically unresectable chondrosarcomas. However, additional in vivo studies will be necessary before applying the proposed therapeutic concept in clinical trials.

\section{Methods}

Chondrosarcoma and Normal Chondrocyte Cell Cultures

Two well-establised Grade II chondrosarcoma and two normal chondrocyte cell lines were used. The chondrosarcoma cell line, JJ012, was obtained from Dr. Joel A. Block (Rush Medical College, Chicago, Illinois, USA), and the other chondrosarcoma cell line, SW1353, was purchased from American Type and Culture Collection (Manassas, Maryland, USA). Two normal articular chondrocyte tissue samples were harvested from patients after obtaining IRB approval. Cartilage specimens were minced with scissors in DMEM (Invitrogen, Carlsbad, California, USA), producing a cell suspension of small tissue fragments. The suspension was pelleted by centrifugation and the tissue fragments were digested enzymatically in phosphate buffered saline (PBS) containing $1 \mathrm{mg} / \mathrm{ml}$ collagenase, 0.15 $\mathrm{mg} / \mathrm{ml}$ DNAse, and $0.15 \mathrm{mg} / \mathrm{ml}$ hyaluronidase (Sigma, St. Louis, Missouri, USA) for 1 hour at $37^{\circ} \mathrm{C}$. The cells were grown at $37^{\circ} \mathrm{C}$ in a humidified atmosphere containing $5 \% \mathrm{CO}_{2}$ and $95 \%$ air. The culture medium consisted of $40 \%$ Dulbecco's modification of Eagle's medium, 40\% MEM- $\alpha$, F-12 (Invitrogen, Carlsbad, CA), 10\% fetal bovine serum (Gembio, Woodland, California, USA), 100 $\mathrm{ng} / \mathrm{ml}$ human insulin (Lilly, Indianapolis, Indiana, USA), $25 \mu \mathrm{g} / \mathrm{ml}$ ascorbic acid, and $100 \mathrm{nM}$ hydrocortisone (Sigma, St. Louis, Missouri, USA). The culture medium was changed every three to four days.

\section{RNA Interference Targeting Anti-Apoptotic Genes and P- glycoprotein}

The siRNAs targeting $B c l-2, B c l-x L, X I A P$ and P-glycoprotein were obtained from Ambion (Austin, Texas, USA). Chondrosarcoma cells that were not treated with siRNAs or those treated with non-silencing siRNAs were used as negative controls. The delivery of siRNAs was verified by using FITC tagged negative control siRNAs (Qiagen, Valencia, California, USA) and X-tremeGENE siRNA transfection reagent (Roche, Branchburg, New Jersey, USA) as a carrier. Manufacturer's protocol was followed for siRNA transfection. We have reported that the optimal siRNA concentration is $1 \mu \mathrm{g} / \mathrm{ml}$ and gene silencing effect of siRNA is maximal on day 2 after siRNA transfection in SW1353 and JJ012 chondrosarcoma cells [4]. Therefore, transfection was carried out using $1 \mu \mathrm{g} / \mathrm{ml}$ of siRNA for single siRNA treatment groups and $0.5 \mu \mathrm{g} / \mathrm{ml}$ of each siRNA for dual treatment groups to make the total amount of siRNA administered $1 \mu \mathrm{g} / \mathrm{ml}$. Doxorubicin was treated 48 hours after siRNA treatment. 


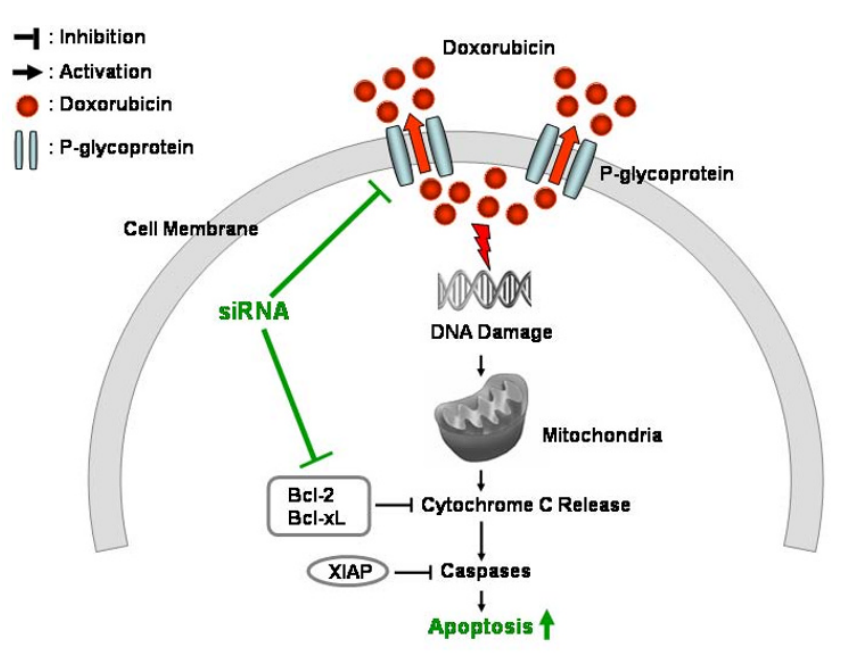

Figure 9

Doxorubicin resistance mechanisms in chondrosarcoma cells. A schematic diagram demonstrates a molecular pathway of apoptosis that is triggered by doxorubicin. Doxorubicin damages DNA. This DNA damage induces cytochorome $C$ release in mitochondria which activates caspases, the effectors of apoptosis. P-glycoprotein inhibits doxorubicin effect by drug efflux. Bcl-2 and $\mathrm{Bcl}-\mathrm{xL}$ block cytochrome c release. XIAP inhibits caspase activation.

\section{Flow Cytometry after Annexin V Staining}

The culture conditions were identical for both control and experimental groups. Chondrosarcoma cells and normal chondrocytes were grown in six-well plates and treated with $0,0.1$, and $1 \mu \mathrm{M}$ of doxorubicin for 24 hours once a confluency of $80 \%$ had been reached. Human embryonic kidney cells (HEK cells) were used as a control to verify the cytotoxic effects of doxorubicin where the dose was chosen based on peak plasma level $(1-2 \mu \mathrm{g} / \mathrm{ml}$ or $1.7-3.4$ $\mu \mathrm{M})$ in patients receiving a standard doxorubicin treatment [30]. Another set of chondrosarcoma cells were pretreated with inhibitors including $\mathrm{Bcl}-2$ inhibitor $(2,9-$ Dimethoxy-11,12-dihydrodibenzo-diazocine 5,6-dioxide and 5,5'-Dimethoxy-2,2'-dinitrosobenzyl, Calbiochem, San Diego, California, USA), C-4 (Calbiochem, San Diego, CA) and embelin (Calbiochem, San Diego, CA) 24 hours prior to doxorubicin treatment or with siRNAs that targeted Bcl-2, Bcl-xL, XIAP and P-glycoprotein 48 hours before doxorubicin treatment. Flow cytometric analysis was used to identify cells undergoing apoptosis. After trypsinizing the cells, they were stained with APC conjugated Annexin V (BD Pharmingen, San Diego, CA). Stained cells were then counted with a flow cytometer (FACS Calibur; Becton Dickinson Science, San Jose, CA).

\section{Doxorubicin Efflux Assay}

Doxorubicin efflux assays were carried out as previously described [7]. In brief, cells were exposed with doxoru- bicin contained medium for 1 hour and washed with PBS two times. Then cells were incubated in doxorubicin-free medium for 1, 6 and 24 hours and harvested for measurement of autofluorescent doxorubicin (excitation wavelength: $480 \mathrm{~nm}$, emission wavelength: $580 \mathrm{~nm}$ ) with a flow cytometer.

\section{Clonogenic Survival Assay}

The clonogenic survival assay was used to determine the capacity for cell survival and proliferation after radiation or chemotherapy [31]. After treatment with siRNA and doxorubicin, 1000 cells from each group were seeded onto $60 \mathrm{~mm}$ cell culture plates containing the culture medium. Fifteen days later, the cells were stained with crystal violet (Sigma, St. Louis, Missouri, USA). Colonies larger than 50 cells were counted at low magnification.

\section{Immunoblotting}

Immunoblotting assays were conducted in order to determine the expression of P-glycoprotein and anti-apoptotic proteins by chondrosarcoma cells and the effect of gene silencing. The cells were lysed using buffer IP (10 mM Tris$\mathrm{HCl}, \mathrm{pH} 7.4,150 \mathrm{mM} \mathrm{NaCl}, 1 \%$ Triton X-100, 0.25\% Nonidet P-40, and $2 \mathrm{mM}$ EDTA) supplemented with a protease inhibitor cocktail (Roche, Branchburg, New Jersey, USA). Equivalent protein extracts (10 $\mu \mathrm{g})$ from each sample were electrophoresed in 4-20\% Tris-Glycine gels (Invitrogen, Carlsbad, CA). For mitochondrial and cytosolic fraction, cells were washed with ice-cold PBS and lysis buffer A (20 mM HEPES pH7.5, 0.1\% BSA, $0.1 \mu \mathrm{M}$ PMSF, $1 \mathrm{mM}$ EDTA, $1 \mathrm{mM}$ DTT, $20 \mu \mathrm{g} / \mathrm{ml}$ leupeptin, 10 $\mu \mathrm{g} / \mathrm{ml}$ aprotinin, $10 \mu \mathrm{g} / \mathrm{ml}$ pepstatin A) containing 250 $\mathrm{mM}$ of sucrose was added. After $10 \mathrm{~min}$ incubation on ice, cells were homogenized with a dounce homogenizer and centrifuged at $700 \times \mathrm{g}$ for $5 \mathrm{~min}$ at $4^{\circ} \mathrm{C}$. Supernatants were centrifuged at $10,000 \times \mathrm{g}$ for $30 \mathrm{~min}$ at $4^{\circ} \mathrm{C}$. The resulting supernatants were used as the cytosolic fraction and the mitochondria pellets were resuspended with lysis buffer A. Equivalent protein extracts $(60 \mu \mathrm{g}$ for mitochondrial fraction and $120 \mu \mathrm{g}$ for cytosolic fraction) from each sample were electrophoresed in 4-20\% Tris-Glycine gels (Invitrogen). The total amount of protein was quantified using the BCA assay. The protein was transferred to an Immun-Blot PVDF membrane (Bio-Rad, Hercules, California, USA) which was then incubated with Bcl-2, Bcl-xL, XIAP (Cell Signaling, Beverly, MA), $\alpha$-actin (Sigma, St. Louis, Missouri, USA), P-glycoprotein (Calbiochem, San Diego, California, USA) and GAPDH antibodies (Chemicon, Temecula, California, USA). The signal strength of each immunoblot band was normalized to GAPDH and quantified using the ImageJ software.

\section{Quantitative Real Time RT-PCR}

Total RNA was isolated from cells using an RNeasy Mini Kit (Qiagen, Valencia, California, USA) according to the 
manufacturer's guidelines. Single stranded cDNA was synthesized from total RNA with the SuperScript III system (Invitrogen). Real time RT-PCR for each target was performed with LightCycler FastStart DNA Master ${ }^{\text {PLUS SYBR }}$ Green I (Roche Diagnostics Corporation, Indianapolis, Indiana, USA) using the Smart Cycler $^{\circledR}$ System (Cepheid, Sunnyvale, California, USA). Primers sets used were: for GAPDH, (5'-AGAACATCATCCCTGCATCC-3') and (5'AGTTGCTGTTGAAGTCGC-3'); for P-glycoprotein, (5'AACAACGCATTGCCATAGCTCGTG-3') and (5'-AGTCTGCATTCTGGATGGTGGACA-3'). The thermal cycling condition consisted of pre-heating $\left(10\right.$ minutes at $\left.94^{\circ} \mathrm{C}\right)$ and 40 cycles of denaturation (10 seconds at $94^{\circ} \mathrm{C}$ ), annealing $\left(20\right.$ seconds at $60^{\circ} \mathrm{C}$ ) and elongation (20 seconds at $72^{\circ} \mathrm{C}$ ). Each mRNA level was normalized with the internal control GAPDH mRNA level.

\section{Statistical Analysis}

Experiments were performed three times and in triplicate at each time. Statistical analysis was performed using the Statistical Package for the Social Sciences (SPSS) software (version 13, Chicago, Illinois, USA). Differences between each control and experimental groups were analyzed by using one-way analysis of variance between groups (ANOVA/Scheffe), and p $<0.05$ was considered statistically significant.

\section{Competing interests}

The authors declare that they have no competing interests.

\section{Authors' contributions}

DK, JY and FL designed research. DWK, KK, MS, JHH and SWS performed molecular study. KK, JHH and SWS performed statistical analysis. DWK, JY and FL participated in data interpretation. DWK, MS and FL drafted the manuscript. All authors read and approved the final manuscript.

\section{Acknowledgements}

This work was supported by the Aircast Foundation Research Grant (FYL). The authors are grateful to Kathryn Kennedy for helpful discussion and critical reading of the manuscript and to Dr. Joel block for presenting JJ0 2 cells.

\section{References}

I. Johnson S, Tetu B, Ayala AG, Chawla SP: Chondrosarcoma with additional mesenchymal component (dedifferentiated chondrosarcoma). I. A clinicopathologic study of $\mathbf{2 6}$ cases. Cancer 1986, 58:278-286.

2. Lee FY, Mankin HJ, Fondren G, Gebhardt MC, Springfield DS, Rosenberg AE, Jennings LC: Chondrosarcoma of bone: an assessment of outcome. J Bone Joint Surg Am 1999, 81:326-338.

3. Terek RM, Schwartz GK, Devaney K, Glantz L, Mak S, Healey JH, Albino AP: Chemotherapy and P-glycoprotein expression in chondrosarcoma. J Orthop Res 1998, 16:585-590.

4. Kim DW, Seo SW, Cho SK, Chang SS, Lee HW, Lee SE, Block JA, Hei TK, Lee FY: Targeting of cell survival genes using small interfering RNAs (siRNAs) enhances radiosensitivity of Grade II chondrosarcoma cells. J Orthop Res 2007, 25:820-828.
5. Rosier RN, O'Keefe RJ, Teot LA, Fox EJ, Nester TA, Puzas JE, Reynolds PR, Hicks DG: P-glycoprotein expression in cartilaginous tumors. J Surg Oncol 1997, 65:95-105.

6. Shen ZN, Nishida K, Doi H, Oohashi T, Hirohata S, Ozaki T, Yoshida $A$, Ninomiya $Y$, Inoue H: Suppression of chondrosarcoma cells by I5-deoxy-Delta I2, I 4-prostaglandin J2 is associated with altered expression of Bax/Bcl-xL and p2 I. Biochem Biophys Res Commun 2005, 328:375-382.

7. Wyman JJ, Hornstein AM, Meitner PA, Mak S, Verdier P, Block JA, Pan $\mathrm{J}$, Terek RM: Multidrug resistance-I and p-glycoprotein in human chondrosarcoma cell lines: expression correlates with decreased intracellular doxorubicin and in vitro chemoresistance. J Orthop Res 1999, I 7:935-940.

8. Pastan I, Gottesman M: Multiple-drug resistance in human cancer. N Engl J Med 1987, 3 I 6: I388-1393.

9. Ambudkar SV, Dey S, Hrycyna CA, Ramachandra M, Pastan I, Gottesman MM: Biochemical, cellular, and pharmacological aspects of the multidrug transporter. Annu Rev Pharmacol Toxicol 1999, 39:361-398.

10. Sonneveld P: Multidrug resistance in haematological malignancies. J Intern Med 2000, 247:521-534.

II. Stein U, Shoemaker RH, Schlag PM: MDR I gene expression: evaluation of its use as a molecular marker for prognosis and chemotherapy of bone and soft tissue sarcomas. Eur J Cancer 1996, 32A:86-92.

12. Kojima H, Endo K, Moriyama H, Tanaka Y, Alnemri ES, Slapak CA, Teicher B, Kufe D, Datta R: Abrogation of mitochondrial cytochrome $c$ release and caspase- 3 activation in acquired multidrug resistance. J Biol Chem 1998, 273:16647-I6650.

13. Condon LT, Ashman JN, Ell SR, Stafford ND, Greenman J, Cawkwell $\mathrm{L}$ : Overexpression of $\mathrm{BCl}-2$ in squamous cell carcinoma of the larynx: a marker of radioresistance. Int J Cancer 2002, 100:472-475.

14. Gilbert MS, Saad AH, Rupnow BA, Knox SJ: Association of BCL-2 with membrane hyperpolarization and radioresistance. J Cell Physiol 1996, 168:1 |4-122.

15. Kaufmann SH, Earnshaw WC: Induction of apoptosis by cancer chemotherapy. Exp Cell Res 2000, 256:42-49.

16. Bold RJ, Termuhlen PM, McConkey DJ: Apoptosis, cancer and cancer therapy. Surg Oncol 1997, 6: |33-| 42.

17. Lima RT, Martins LM, Guimaraes JE, Sambade C, Vasconcelos $M H$ : Specific downregulation of bcl-2 and xIAP by RNAi enhances the effects of chemotherapeutic agents in MCF-7 human breast cancer cells. Cancer Gene Ther 2004, I I:309-3 I6.

18. Amantana A, London CA, Iversen PL, Devi GR: X-linked inhibitor of apoptosis protein inhibition induces apoptosis and enhances chemotherapy sensitivity in human prostate cancer cells. Mol Cancer Ther 2004, 3:699-707.

19. Jiang X, Dutton CM, Qi W, Block JA, Brodt P, Durko M, Scully SP: Inhibition of MMP-I expression by antisense RNA decreases invasiveness of human chondrosarcoma. J Orthop Res 2003, 2 I: $1063-1070$.

20. Scully SP, Berend KR, Toth A, Qi WN, Qi Z, Block JA: Marshall Urist Award. Interstitial collagenase gene expression correlates with in vitro invasion in human chondrosarcoma. Clin Orthop Relat Res 2000:291-303.

21. Uria JA, Balbin M, Lopez JM, Alvarez J, Vizoso F, Takigawa M, LopezOtin C: Collagenase-3 (MMP-I3) expression in chondrosarcoma cells and its regulation by basic fibroblast growth factor. Am J Pathol 1998, I53:91-101.

22. Mori T, Doi R, Kida A, Nagai K, Kami K, Ito D, Toyoda E, Kawaguchi $Y$, Uemoto S: Effect of the XIAP inhibitor Embelin on TRAILinduced apoptosis of pancreatic cancer cells. J Surg Res 2007, I 42:28I-286.

23. Kim YK, Song YJ, Seo DW, Kang DW, Lee HY, Rhee DK, Han JW, Ahn CM, Lee S, Kim SN: Reversal of multidrug resistance by 4chloro-N-(3-((E)-3-(4-hydroxy-3-methoxyphenyl)acryloyl)phenyl)benzamide through the reversible inhibition of P-glycoprotein. Biochem Biophys Res Commun 2007, 355: I36-I 42.

24. Enyedy IJ, Ling Y, Nacro K, Tomita Y, Wu X, Cao Y, Guo R, Li B, Zhu $X$, Huang $Y$, et al:: Discovery of small-molecule inhibitors of Bcl-2 through structure-based computer screening. J Med Chem 200I, 44:4313-4324.

25. Gottesman MM: Mechanisms of cancer drug resistance. Annu Rev Med 2002, 53:615-627. 
26. Ueda K, Cardarelli C, Gottesman MM, Pastan I: Expression of a fulllength cDNA for the human "MDRI" gene confers resistance to colchicine, doxorubicin, and vinblastine. Proc Natl Acad Sci USA 1987, 84:3004-3008.

27. Mantovani I, Cappellini A, Tazzari PL, Papa V, Cocco L, Martelli AM: Caspase-dependent cleavage of 170-kDa P-glycoprotein during apoptosis of human T-lymphoblastoid CEM cells. J Cell Physiol 2006, 207:836-844.

28. Nakagawa $Y$, Abe $S$, Kurata M, Hasegawa M, Yamamoto K, Inoue M, Takemura T, Suzuki K, Kitagawa M: IAP family protein expression correlates with poor outcome of multiple myeloma patients in association with chemotherapy-induced overexpression of multidrug resistance genes. Am J Hematol 2006, 8I:824-83I.

29. McManus MT, Sharp PA: Gene silencing in mammals by small interfering RNAs. Nat Rev Genet 2002, 3:737-747.

30. Speth PA, Linssen PC, Boezeman JB, Wessels HM, Haanen C: Cellular and plasma adriamycin concentrations in long-term infusion therapy of leukemia patients. Cancer Chemother Pharmacol 1987, 20:305-310.

31. Franken NA, Rodermond HM, Stap J, Haveman J, van Bree C: Clonogenic assay of cells in vitro. Nat Protoc 2006, I:23 I5-2319.

Publish with Bio Med Central and every scientist can read your work free of charge

"BioMed Central will be the most significant development for disseminating the results of biomedical research in our lifetime. "

Sir Paul Nurse, Cancer Research UK

Your research papers will be:

- available free of charge to the entire biomedical community

- peer reviewed and published immediately upon acceptance

- cited in PubMed and archived on PubMed Central

- yours - you keep the copyright
BioMedcentral 